\title{
Toward Safe and Usable Technologies for Autistic: Risks Identification and Mitigation Guidelines
}

\author{
Nesrine Mezhoudi ${ }^{1}$, Hina Gull${ }^{1}$, Mohammed A. Alqahtani' ${ }^{1}$, Nahla El-Haggar ${ }^{2}$, Moez Ayachi ${ }^{3}$ \\ ${ }^{1}$ Department of Computer Information Systems, College of Computer Science and IT, Imam Abdulrahman Bin Faisal University, \\ P. O. Box 1982, Dammam, Saudi Arabia \\ ${ }^{2}$ Department of Computer Science, Community College, Imam Abdulrahman Bin Faisal University, Dammam, Saudi Arabia \\ ${ }^{3}$ General Study Department, Dammam College of Technology, Dammam, Saudi Arabia \\ Email: nimezhoudi@iau.edu.sa,hgull@iau.edu.sa,maqhtani@iau.edu.sa, naalhagga r@iau.edu.sa,moez.ayachi@fsg.rnu.tn
}

How to cite this paper: Mezhoudi, N. Gull, H., Alqahtani, M.A., El-Haggar, N. and Ayachi, M. (2019) Toward Safe and Usable Technologies for Autistic: Risks Identification and Mitigation Guidelines. Open Journal of Applied Sciences, 9, 26-44. https://doi.org/10.4236/ojapps.2019.91004

Received: January 3, 2019

Accepted: January 26, 2019

Published: January 29, 2019

Copyright (c) 2019 by author(s) and Scientific Research Publishing Inc. This work is licensed under the Creative Commons Attribution International License (CC BY 4.0).

http://creativecommons.org/licenses/by/4.0/

\begin{abstract}
Recent advances in technology provide countless innovative solutions and applications for supporting children with autism in educational learning and personal development. This result is an increasingly recognized need to deal with new and unexpected risks and issues such as social exclusion. Diverse advanced technologies were aimed to support learning activity from different perspectives with multiple strategies. However, despite the significant amount of work and explored technology, several common risks pop up due to user's vulnerability to diverse risks such as negative screen effects. Accordingly, there is still plenty of room for improvement in this regard. To address these vulnerabilities and gaps, this paper aims at identifying issues and challenges improving the technology applied for Autism Spectrum Disorders and autistics dedicated applications. It put forward requirements and design decisions supporting safe autistic dedicated interaction with regards to ISO31000 risk management process.
\end{abstract}

\section{Keywords}

Autism Spectrum Disorders, Supportive Technology, Risk-Awareness, ISO31000, IT Risks

\section{Introduction}

Today's use of technology is very practical, as it tends to yield real life benefits, however many risks results from technologies associated mainly with uncontrolled use. In this paper, we focus on technology's risks affecting autistic people 
and their mitigation in order to provide them safe usable and reliable interactive environment.

Since the beginning, IT has delivered more advanced technologies to support human social and private lives. With the course of time, use of technology has played a prominent role in research and several clinical practices. In this work we consider the use of technologies to deal with users with Autism Spectrum Disorders (ASD). Autism spectrum disorders (ASD) is defined as deep deficit in social communication and interaction skills. Entities with Autism suffer consequences with respect to the deficiency in their social interaction. These consequences can both be direct or indirect having adverse effects on individuals. They have very limited patterns of behaving, communicating and even daily life interaction. As IT has enabled change throughout our life, any activity that is connected to IT should therefore benefit from a differential treatment facilitating children's development without additional burden.

New technological advances support the social aspect from different perspective. It looks promising to support more effective study, diagnosis and treatment strategies along with enhancing the eminence of life for the individual with ASD and their caretakers and relations. A number of studies conducted over the years have shown that the users with ASD are getting immense benefits by use of digital applications. For example, Dena Aucoin, the Assistant Academic Chair in the Educational Studies program at Kaplan University believes the use of application for kids with ASD can greatly support learning and social development. This belief can be supported by seeing the development of multiple application and technology which supports people especially children with ASD. Such ASD related applications can be exemplified, using Computer-Assisted Technologies to improve and elevate social interaction of children, especially development in their communication and language. Such applications include functionalities such as learning new skills accurately, independently, and efficiently. Some other technologies have also taken part in improving quality of life of autistic children as they have been globally applied. Examples of such technologies are online communities and social media, robotics, assistive devices, computer-aided instruction, video modelling, virtual reality, vocal communication, bio-sensing, computer-training and games.

However, since ASD is extremely wide and varied, it is frequently misunderstood, and attitudes toward autism can be erroneous. Meanwhile, advanced applications were developed to target autistic kids through a virtual simulation that render common experiences for people with autism [1]. Further, considering the hypothesis that the support of application for autism having multiple communal and emotive aspects, contribute to the elevated use of technology by the families facing ASD. Without forgetting that a brain with autism is more sensitive and less resilient for experiencing negative screen effects. Assuming that every child is different and unique, besides that each ASD case suffers from different vulnerabilities with diverse intensity [2], different learning scenario need to be tailored and adapted every specific case to meet his own preferences and accor- 
dingly improve his learning experience.

The study in hand focuses on potential improvement of application for kids with ASD. It aims at exploring learning application benefits, potential risks, common requirements and main trade-offs. The paper also presents a roadmap that leads stakeholders for applying technology in dealing with children suffering from Autism Spectrum Disorder. Multiple scenarios of different applications are used as example, leading to the development of analogous but more personalized applications. This paper presents several possible approaches that support the development of adaptive applications in an optimal way. This works is supposed to be a step towards recognized screen-based software claiming to reduce autistic behavior or to improve interaction and reading capabilities of children. Furthermore, we assume that a user centered interactive experience will reduce the possible stimulant effects of screen. This extravaganza aims at providing guidelines for the development of ASD application with more appropriate scenario. Intended application should consider different autism deficits and deal with diverse case vulnerabilities within a user-centered perspective. Therefore, we identified potential risks from different point of view. In addition, we identified the main trade-offs and common requirements for using technology driven solution for kids with ASD.

The paper has following organizational structure: Next section will comprise of the literature study, Section 3 consists of the roadmap, Section 4 describes potential risks of technology on autistic kids, Section 5 has all communal requirements and the design decisions, Section 6 conclude by discussing the contributions and the future works.

\section{Related Work}

In today's world, technology has captivated every area of our life. It is not only beneficial to us in multiple ways, but it can also be used to overcome our shortcomings. Technology has helped to treat multiple patients and diseases. For instance, for individuals with autism and especially children, its role becomes more and crucial.

\subsection{Autism Spectrum Disorder}

It represents a mental disorder affecting mainly the development of communication and behavioral skills among subject. ASD mental disorder involves a diverse combination of brain expansion in some areas and reduction in others, which may be reflected through well-developed skills and/or different level of disability. Despite the high importance associated with ASD and the increasing number of diagnosed cases, still there is no known cure for ASD. Existing treatment are mainly focused on reducing ASD associated deficits increasing the subject independence and to improve their quality of life and functional autonomy.

Diverse technologies show a great effectiveness in improving multiple dimen- 
sions and capabilities of children such as their social interaction and ability to learn new ideas and things. Some technologies have been successfully applied to support the acquisition of daily task for autistic such as Video modeling, which consist of recording and showing learner a model, performing the behavior or skill.

\subsection{ASD Supporting Technologies}

This section briefly discusses existing works integrating technology for supporting ASD kids to improve their ability to be autonomous and communicate. Since early 70's a number of technologies has been applied to support different autism deficits and many studies demonstrate its effectiveness. Example of deployed technologies for supporting autistic children are interactional robots [3], virtual characters [4] [5] virtual reality [6] and video games. Some other innovative technologies are also being applied and used for people having ASD such as IOT, Social media/network, Virtual reality, Augmented reality, Mobile Technology, Video self-modelling (VSM) etc.

Social Media: It is recommended mainly as a replacement of real interaction. Social media provide autistic individual with a new interactive experience that is designed to tackle their deficits in verbal and nonverbal communication, and poor social reciprocity. Social media offers attractive and collaborative means for people having ASD, specially the people having specific needs for screen-based intervention [7] [8] [9]. It can provide easy and relaxed way of communication specially for the autistic children. Studies have shown that that not only children but also parents for autistic children find help and much needed support in online communities and forums. They help them to deal with the society with similar patterns as they interact in face to face communication. Study conducted by [10] showed that the social media is also used as a source to find information about autistic children. It helps to get knowledge about health. According to them $28 \%$ of the participants in their survey study used social media to enhance their acquaintance of knowledge about autism. People also used social media for educating themselves about autism. They used it meet and communicate with the people having same problems. By this way they find motivation to deal with such situations. According to another study [2] not only children but also parents use social media to help their children who are suffering from autism. According to them social media allows parents to share their own experiences, get ways to talk and communicate with other parents, obtain information and resources etc. which helps the child a lot to deal with autism. According to parents through social media interaction their child has gained more confident and overcome the fear of communication to some extent [11] [12].

Video Self-Modelling: VSM is mainly about a video modelling that involves the user himself/herself as the model who perform an appropriate behavior successfully [13]. Several works demonstrated the effectiveness of VSM for many deficiencies in the interaction of autistic persons in their communication and behavior. A study [14] shows the analysis and results of VSM on the children who are suffering from ASD. The study was designed to show the behavior of 
children across multiple factors such as language, inaugurating and starting different actions and interaction steps, temperament, and anger. Several factors of design were considered and analyzed to check the students and their behavior over a time in different studies. These studies also depict the performance of students. In one of the studies, five participants took part in the experimentation. According to results, all participants show elevated performance and this performance gain and elevation were maintained after the treatment finished [15].

Augmented Reality: Augmented reality refers to the simulation produced by computers, which contains components such as $3 \mathrm{D}$ graphics, audio and video. This simulation is generated in the real time on the rely of real world. Zhen Bai, et al. [16] has conducted a study for applying augmented reality methods with children having Autism Spectrum conditions of ages $4-7$. The children exhibit positive results for ASC. Makers in the form of toys were given to the students. These makers were shown to the children on screen as well creating their reflection. These reflections have same feel and look of a mirror. Findings exhibit the sue of VSM as a worthy addition to the technology, that can bring positive change in behavior of people with ASC. Another study carried out by Lizbeth and Monica [17] aid mentors as well as the care takers of children using augmented reality. The study comprises about eight weeks and involve three classrooms, each having seven mentors and several children suffering from ASD. In the real environment they show the ways to provide children with training about the usage of AR systems. In 2014, Lakshmi prabha et al. [18] uses very commonly known technique of Applied behavior analysis along with augmented and virtual reality to monitor the behavior of autistic children. System was proved to be very helpful in teaching children and identifying new graphics. Qingguo $\mathrm{Xu}$, et al. [19] uses glass platform methods to take interviews of children with ASD. Cameras and microphones were used as inputs for the system [20].

Virtual Reality (VR): It is defined as an imitation of the reality which is based on 3D images and graphics. VR helps in improving learning process of children as it allows trainers and psychotherapists to provide them with some safe and risk-free surroundings to learn. Virtual reality (VR) is also considered an adequate tool for children to get knowledge of communication skills in social environments, learn social interaction and help them in identifying and responding to non-vocal prompts. Bricken [21] and Strickland [22], added to the arguments by arguing that VR is valuable and advantageous for whole learning process as it takes the needs and wants of the user into consideration and provides learning environment that best suits the user's requirements. It can be illustrated by an example as we can control the virtual settings and the input to the system, so that it can be matched with the experience and tolerant level of people. So, VR is capable for providing us customizable treatments based on individuals which can even be helpful for the patients having multiple symptoms of autism. On the top of that, virtual learning environments provide a less risky and more pardoning atmosphere as it reduces the intricacy of social interactions [23]. 
Wearable Technology: Wearable technology has gone under a radical development because of continuous addition of multiple new features to make our daily life interesting and easier. Wearables are clothing and accessories (watches, bracelets, etc.) incorporating computer and advanced electronic technologies giving a user feedback of their actions or unique ways of controlling or interacting with other technologies. General Examples: Bracelets like FitBit and WI things (track movement, assist with navigation, monitor fitness goals, etc.), smart watches like Samsung Gear 2 and Apple's iWatch (sync with smartphones to make calls, display information, etc.), and Google Glass. Implications to Disability: This technology offers flexibility to those with disabilities in the different way a user can interact with technology. Wearables also offer a more personable way than ever before to interact with technologies. Multiple behavioral arbitration for social skills have been proposed, including video self-modeling [24], social stories for autistic kids [25], Trainers and their groups to improve social skills [26], different therapies to improve cognitive skills [27] and training in different schools [28]. Most of these intercession and arbitrations are difficult and costly to implement as they require spending money on human resources and adequate training. This issue is aggravated by the fact that an improved learning and daily life-based skills needs continuous efforts and repetition over a long time of weeks even months. Resource requirements of these arbitration is the major hindrance in the treatment as shown by service wait times that range from months to years [13]. These barricades can be condensed by using technology for treatment delivery. The use of technology has proven to be an inspiring learning way for children with ASD [29] [30] [31], and this is depicted in various studies that children's social interaction and cognitive skills are improved when technology such as computers and other devices are used [32] [33] [34]. Specially, the increasing use of multitouch screens, tablets and other devices as instructional resources has depicted an improvement in children's performance. Children feel safer and controlled, which is lacking before their interaction with other people [35]. This line of teaching new skills has opened a horizon for development of multiple application for skill learning, behavior supervision, and helps in improving social communication [33] [34].

Mobile Technology: Mobile technology and ad hoc applications for ASD people, can be used side by side to identify the needs of ASD individuals. Portable speech generating devices are very helpful tools for autistic individuals who specifically suffer from speech limitation problems. In-spite of the fact that this technology is new but is warmly welcomed by the autism community. User centered design involving trainers, mentors and parents of can be very beneficial for the implementation of an application which hemp people suffering from ASD. Mobile technology is becoming popular among the people who has special needs. Mobile technology provides multiple features such as portability, usability in terms of touch screens and low cost. Touchscreen proved to be very useful feature for those who have weak motor skills. It provides very interactive and 
easy way for social communication specially when autistic patients want to communicate with their friends and families [36]. There are some other methods and tools containing mobile technology was introduced for the preliminary diagnosis of autism. Continuous recording and monitoring feature of mobile devices can be used to study and monitor the behavior of autistic people.

\section{IT/ASD: A Roadmap of Technologies Application for Children with ASD}

Although innovative technologies are already functional to support children with ASD, the work done till now is spare and is not combined yet. Given that there is no agreed reference for evaluating interactive systems for autistic people nor a common standard for guiding stakeholders in the development of appropriate interactions to provide effective and reliable support for ASD cases. Despite the role of IT in targeting and supporting people with disabilities in various human functioning areas, there is lack of consideration of related risks. Ignoring Autistics vulnerability to brain-related impacts of interaction represent a serious threat to end-users and covering up such issues can make it worse. Accordingly, we argue for a thorough understanding of the interaction and technologies related risks. Moreover, dealing with interaction related risks at an early stage aids systems designer in reflecting them in more potential interactive scenarios where risks are successfully reduced and/or managed.

This section provides a unified view of IT support for autistic children. It brings together considered core deficits and addressed areas of human functioning. Further the roadmap shows the support of risk in provided solutions. Three core deficits are recognized and correspond to the identified ASD impairment related to the neurodevelopmental disorders [37]. In Figure 1 we put forwards main deficits with samples about how each deficit manifests in different ways in function of the autistic age and autism level.

Table 1 list different potential scenario of deploying new technology for autistic dedicated systems. Precise enhancements are required to model and implement diverse solutions that will be adequate with the generic scenario. For

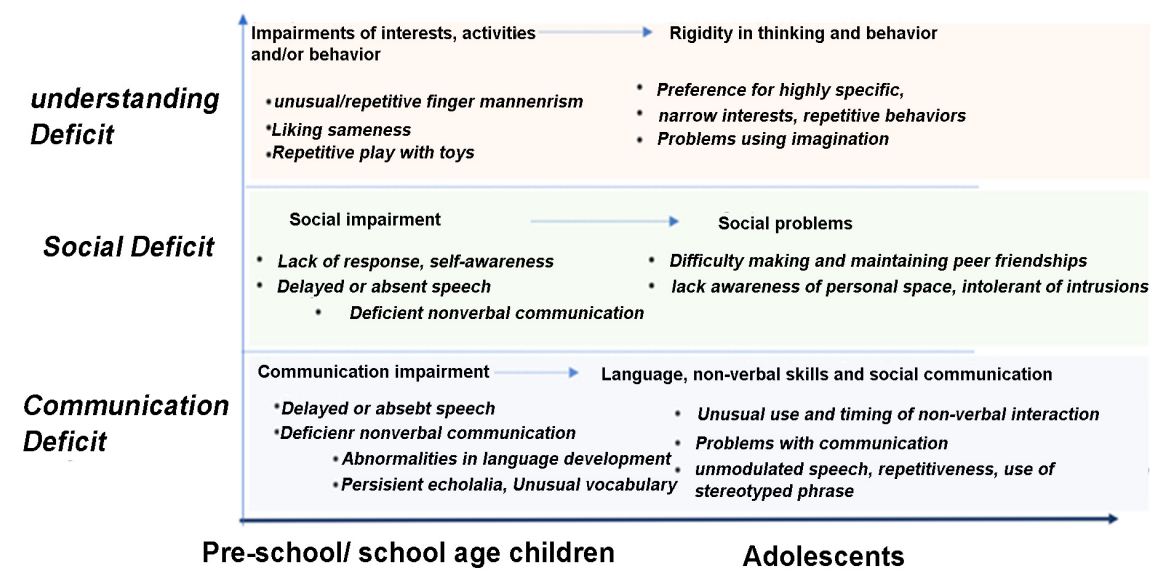

Figure 1. Three main deficit. 
Table 1. Guidance Roadmap for technologies support for autistics.

\begin{tabular}{|c|c|c|c|c|c|c|c|c|c|c|}
\hline \multirow{2}{*}{$\begin{array}{l}\text { Advanced } \\
\text { Technology }\end{array}$} & \multirow{2}{*}{ Generic Application Scenario } & \multicolumn{3}{|c|}{ Addressed deficit } & \multicolumn{5}{|c|}{ Addressed human functioning areas } & \multirow{2}{*}{$\begin{array}{l}\text { Risk } \\
\text { Identification } \\
\text { and Support }\end{array}$} \\
\hline & & Communication & Social & $\begin{array}{l}\text { Imagination of } \\
\text { others mind }\end{array}$ & $\begin{array}{l}\text { Executive } \\
\text { function }\end{array}$ & Social & Academic & Adaptive & $\begin{array}{l}\text { Motor } \\
\text { and play }\end{array}$ & \\
\hline Virtual Reality & $\begin{array}{l}\text { Social Cognition Training aimed to } \\
\text { improve social skills among end } \\
\text { user [23] }\end{array}$ & & - & - & - & - & & & & $\circ$ \\
\hline $\begin{array}{l}\text { IOT and } \\
\text { were able } \\
\text { technologies }\end{array}$ & $\begin{array}{l}\text { Deploying smart a small objects offring } \\
\text { an assistive role for autistics mainly kids. } \\
\text { Such as Ambient Assisted Living (AAL), } \\
\text { which supports children with autism in } \\
\text { their daily life by allowing a safer and } \\
\text { more dependent daily routine } \\
\text { [22], }\end{array}$ & & - & & & & - & & & \\
\hline $\begin{array}{l}\text { Social media/ } \\
\text { network }\end{array}$ & $\begin{array}{l}\text { Promoting the social interaction } \\
\text { throughout increasing the accessibility of } \\
\text { social media platforms, for exemple chat } \\
\text { rooms, instant messaging, and social } \\
\text { networks. [10] [11]. }\end{array}$ & & - & & & - & & & & $\circ$ \\
\hline $\begin{array}{l}\text { Augmented } \\
\text { Reality }\end{array}$ & $\begin{array}{l}\text { Mainly used for teaching important social } \\
\text { capacities allowing a better understanding } \\
\text { of the facial languages and emotions of } \\
\text { others during communication } \\
\text { [31] }\end{array}$ & & & - & & & - & & & $\circ$ \\
\hline $\begin{array}{l}\text { Video self- } \\
\text { modeling } \\
\text { (VSM) }\end{array}$ & $\begin{array}{l}\text { In intended mainly to teach autistics kids. } \\
\text { It allows an individual to learn an action } \\
\text { or a skill by looking at the video of that } \\
\text { model which indicate that skill. } \\
\text { [13] [14] }\end{array}$ & - & () & - & - & () & - & - & & \\
\hline $\begin{array}{l}\text { Mobile } \\
\text { technology }\end{array}$ & $\begin{array}{l}\text { Mobile are mainly deployed as assessment } \\
\text { tools for initial diagnosis of autism, and } \\
\text { continuous observation throughout a } \\
\text { patient's therapeutic intervention. }\end{array}$ & & & & & & & & & $\circ$ \\
\hline $\begin{array}{l}\text { Augmentative, } \\
\text { Adaptive and } \\
\text { Assistive } \\
\text { technologies } \\
\text { - Robotics }\end{array}$ & $\begin{array}{l}\text { Mainly used to maintain, arise or improve } \\
\text { the functional know-hows of autistics and }\end{array}$ & & & & & & & & & \\
\hline $\begin{array}{l}- \text { Motor-Sensory } \\
\text { Aids } \\
\text { - Medical } \\
\text { devices } \\
\text { - Wearable } \\
\text { technology }\end{array}$ & $\begin{array}{l}y \text { in general individual with neural } \\
\text { disabilities, such as theory of mind } \\
\text { training [17] [18] [19] }\end{array}$ & & - & () & - & & & - & - & () \\
\hline
\end{tabular}

Legende: $\bullet$ Completely supported; Partially supported; $\odot$ : Not supported; Not specified.

instance, relating to the application of virtual reality, for supporting social skills, attributes that are gathered from the background-based information can be considered, e.g. the existence of visual impairments of the user, availability of input and output [38]. Advanced technology can target a variety of human functioning areas. To establish a boundary for this work, we bring together areas that are related to at least one of the main identified deficits. We define five main functioning areas where technologies contribute supporting identified impairments.

- Executive Functions This area support goal-oriented comportment and self-awareness, for instance problem solving and the capacity to realize the 
mental states of oneself and others.

- Social support interactions skills and the ability of building relationship, as well as social language skills and the ability to communicate efficiently and comprehend other.

- Academic area reflects different skills such as math, language and arts etc.

- Adaptive area involves all required skill for supporting the autonomous achievement of daily living activities, such as dressing, toileting and setting the table.

- Motor and play area covers visual, oral, and motor skills that a child needs to interact efficiently, to participate in games and daily living activities.

In this respect, IT is playing a viable role for the common good. However, there has been a clear sign that stakeholders must have a clearer awareness of risks, regardless of the technology used, the end user capability and addressed performance. We argue for considering ASD's vulnerability to screens at an early stage when designing application and during use.

In Table 1, we established a roadmap that provides the guidelines for stakeholders to apply technology and advanced algorithms in different ASD dedicated solution. Main potential application scenarios are defined, favoring the development of similar applications in an appropriate manner. This roadmap provides guidance for the development ASD dedicated IT solutions, considering different functional areas, deficits and scenarios of use. We also identified their level of security appropriate to the risk presented. Furthermore, road map shows a need for a clearer identification, analysis and mitigation plan of risks in order to enhance implementation efficiency. Such increased consideration of risks related to technology use for autistics, especially kids, can serve as a basis for less risky solutions due to the possibility of operating an adaptive, risk-aware, user-centered technological support.

For each implementation of scenarios listed in Table 1, there is special requirement and solution, however they have a common shortage of identifying and mitigating potential interaction risks. Most application are implementing specific refinements to fit effectively the intended functional requirement about the targeted end user and diagnosed autism level. For instance, regarding the application of Video self-modelling (VSM), the technology focus on the definition and improvement and acquisition of specific social skill in a particular area [39], however its application shows many limitations with kids under 4 years. Further potential risks were not clearly identified, cited neither addressed by most of the works reviewed in this section. For example, only Wearable technology application [40] mentioned that the lack of understanding of user preferences and design factors may lead to a lack of usability risks. Despite the importance of user's acceptance in existing IT based software solution, the risk of inappropriate designs was only partially addressed by [40] while other application did not mention and/or incorporate any risks factor for supporting their usability. Given that there is no agreed definition of risk that provides adequate guidelines to stakeholders in selecting and implementing technology to provide 
an effective support to the end users. In the following section we provide a unified view of interaction. Related risks that can be considered and mitigated throughout applications from an early stage of the development process and during use.

\section{ASD Interaction and Risks Awareness}

All human activities are done at risk of failure. However, the risk' impact is not always limited to the task achievement but in some case, it can affect the end user. Designers may not be aware of the user vulnerability to design solution including software, hardware and interaction scenario. Another illustration of vulnerability is formed by the ubiquity of application. Despite the great role of technology-based solution that allow continuous outpatient monitoring and progress tracking, there is a persistent and important patient-related issue, because an autistic brain has inherent characteristics that screen time exacerbates.

The diversity of cases with autism spectrum disorder shows challenges on interfaces and sensors that must be tackled together for the technology to be effective. Three main issue were identified related to the sensing technologies themselves, the diverse nature of the subjects and the environment of the experiments could not be identified [41] [42], the difference of cognitive perception and processing, [43], and devices that do not allow autistic to interact normally and disturb their focus [44].

\subsection{Support of Risk Management Process: ISO 31000 [38]}

Further the diversity of technologies and their valuable application for autistic kids, increase the number of potential risks and/or side effects that need to be well explored and considered. Recognizing that special brain means special risks, to promote risk-mitigation when designing autistic' dedicated application becomes crucial. New technological advances shift dealing with risk from 'preventive actions' to 'action to address risks.

According to (ISO 31000), requirement about risks and chances do not necessitate a formal risk management system. Though, it requires a clear identification of 'what are the risks' and 'how they will be addressed' throughout determining risk Severity and Probability. ISO 31000 identify a risk management framework, and a risk management process which support a systematic application of policies, procedures and practices. Further it establishes the context and assess, treat, monitor, review, record and report risk [45] [46] (Figure 2).

Risk assessment and risk treatment are at the center of the process. Risk assessment is depicted as a subprocess having the three stages of risk identification, risk analysis and risk evaluation. The risk identification involves finding, recognizing and describing risks that might help or prevent achievement of objectives and the variety of tangible or intangible consequences. The risk analysis consists of investigating the nature and characteristics of risk, determining the level of risk, and identifying its sources, consequences, probability, measures, contexts etc. The risk evaluation is depicted throughout a decision support 


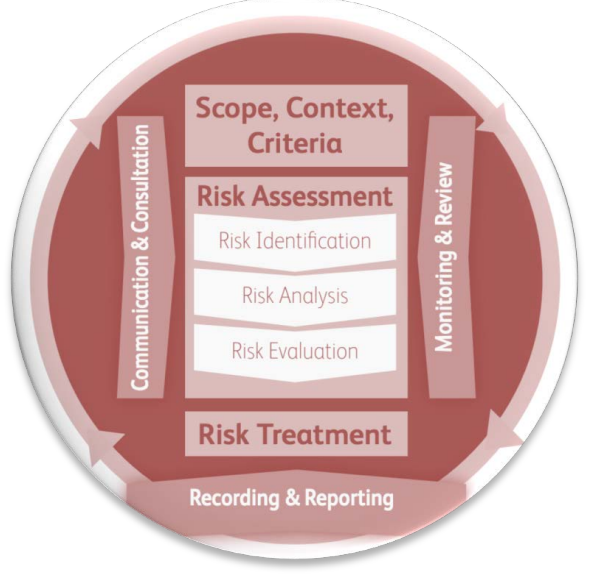

Figure 2. Risk Management Process ISO 31000 [45].

comparing the consequences of the risk analysis with the recognized risk criteria to determine the significance of risk. All principles of risk management have been recognized by ISO 31000 as the key criteria for successful risk management. By the same token, we argue that an explicit and early support of risk will assist all stakeholder 'efforts for a better trade-off, for the system, between acting as a supporter and acting as a stimulant. Further, addressing risks within a user (case)-centered approached of interaction risks, and an interaction derived consideration of identified risks. Such consideration will contribute the interaction experience outcomes, and it can enhance the satisfaction level and performance of autistics users through handling their extra vulnerability for different causes.

\subsection{Autistic Interactive System: Risk Identification}

Autistic interactive systems share all risk identified in a normal interaction, however special risks should be identified and considered. A first class of medical risk derived from the main deficit identified earlier. Medical related risks reflect kids with ASD vulnerability to various brain-related impacts of screen time. These medical risks or interaction "side effects" include hyperarousal and dysregulation as well as technology addiction. Second, there is the HCI risks affiliated to the effectiveness of using the information system (software applications). Within this prospect, we established in this section the risk identification phase as a first step toward the full support of risk management in autism dedicated interactions. This phase consists on recognizing and describing risks that may counteract the achievement of the objectives and expected consequences.

Medical identified Risks: Autistic kid's vulnerability to screen is quite high compared to normal kids. Assuming that special brains have special risks, a brain with autism has inherent characteristics that screen time exacerbates. Several diagnosed factors that contribute in this risk. Following are some identified risks stimulant.

Inflammation of the nervous system: The impact of screen addiction and internet addiction on brain is widely discussed. It is assumed that such addiction 
disrupts nerve wiring in the brains of human with or without ASD, keeping in mind that will inevitably be more exposed to those effects. Such addiction results mainly in a level of brain damage normally seen in heavy substance abusers such as alcohol, cocaine and cannabis. According to Dr Victoria L. Dunckley [47], screen time may intensify the brain inflammation with different related factors such as the increased stress hormones, suppressed melatonin, and non-restorative sleep.

- Social and communication deficits: As an ASD symptom this deficit is mainly recognized by impaired eye contact and difficulty reading facial expressions and body language, low empathy, and impaired communication; At this level screen time accentuate the negative effect of impeding the development of interactive and communication skills.

- Sensory and motor integration issues: [25] similar to tics; screen time has been linked to sensory-motor delays and worsening of sensory processing. Cris Rowan [48] observed a negative impact of screen time on motor proficiency of kids at ages 4, 5 , and 7 . This analysis result foregrounds the adverse influence of screen time on motor proficiency.

- Friable Attention system: poor executive functioning, and "reduced bandwidth" when processing information (Just) [49]; screen time likewise fractures attention, depletes mental reserves, and impairs executive functioning [50].

Interaction Related Risks: Despite all HCI's research on ergonomic principles and design guidelines to improve interaction and support all users in different tasks, there are still many HCI risks that need to be considered and mitigated during interaction. An extensive list of risk was identified and document by NASA [51]. In what follows we discuss only interaction related risks.

- Risk of Inadequate Human-Computer Interaction: Eight factors are identified and contributes to this risk, according to the Human Factors Analysis and Classification System (HFACS): 1) Requirements, policies, and design processes, 2) Information resources/support, 3) Allocation of attention, 4) Cognitive overload, 5) Environmentally induced perceptual changes, 6) Misperception/misinterpretation of displayed information, 7) Spatia [51].

- Risk of Inadequate Mission, Process and Task Design: This risk is mainly about the consideration of the human condition as it relates to task performance. The UI design is required to address and optimize the end-user performance. This includes review of tasks, schedules, training, and procedures to ensure they take into account human capabilities and limitations, and inevitable physical and cognitive changes that occur while on a space mission [51].

- Risk of Performance: Errors Due to Training Deficiencies: Focusing on the training deficiency risk became more crucial in the case of intelligent UI. It is necessary to develop an understanding of how training can be tailored to better support long-duration operations. However, in case of advanced intelligent algorithms there is the risk of losing transparency in the decision- 
making process and consequently losing control. Accordingly, both Transparency and predictability need to be guaranteed for those they govern [51].

- Risk of Adverse Cognitive or Behavioral Conditions and Psychiatric Disorders: Despite the greater dependence on HCI in the context of assisting kids, there is a risk that critical information systems will not support all children effectively. Resulting in increased user's errors and inefficiencies, failed learning mission and program objectives. Assuming that the early detection of such risk factors during interaction is critical to reduce the development of behavioral and/or psychiatric problems among user, it is recommended to develop modules and measures for monitoring and evaluating behavioral health during interaction mainly when users are kids.

\section{Finding and Analysis}

\subsection{Potential Trade-0ffs}

Although innovative technology may be the only way to ensure a set of benefits for autistic user since there is no medical treatment for the core symptoms of Autism. Care must be taken during the selection of technology to increase and/or maintain its effectiveness for different ASD case. Clearly, there are several trade-offs that can be expected by targeting only ASD major deficit or simply dealing with a specific case or ASD type.

Researcher need to not only consider user with different ASD levels but further give a big importance to each user's preferences, skills, as well as his or her culturally and linguistically backgrounds. Existing application with well-defined task offers a unique interaction model which may be not equally understood by different kids, the interaction results can: bother, annoy, confuse or even prevent users and the whole interaction session from achieving their actual goals. Further it degrades the understanding of the emergent dynamics of interaction and reduce usability and reliability. Reliability is concerned with identifying, modelling, and quantifying the probability of human errors during interaction with systems.

Accordingly, user must be always at the center of any design decision, risk must be well identified and addressed during interaction. Finally, application should be able to evaluate each interaction and mitigate risks to confirm that the results achieved are convenient according to the main system goals and different kids interests. The common requirements are presented below and aimed at fulfilling interaction goals with different innovative technologies, but also reducing risks and errors.

\subsection{Common Requirements}

The above identified risks are of paramount importance to the success of ASD interactive system. Identifying and addressing them at an early stage of the development process is expected to contribute to the improvement of systems usability. By analyzing the related work, concerns could be summed in three main 
points; shortened support of interaction related risk, lack of exclusive user consideration and advanced adaptation that involves risk management. More specifically, the main shortcoming is the absence of a system that reinforces usability and supports a well-identified risk management process at an early stage of development.

By recognizing and investigating ASD associated interaction risks determining their scope, evidence and consequences treating them can become less complicated.

Accordingly, a more efficient and effective automated risk management support may be enabled by means of technology. This support requires active cooperation of HCI' usability guidelines, intelligent machine learning algorithms and risk management standards, and manifested throughout:

1) A well consideration of end-user at the center of the interactive experience by offering solutions that guarantee higher usability level for diverse user profile with varied diagnosed autism level and different backgrounds.

2) A continuous improvement of the system' Decision-Making Process by considering circumstances of the previous interaction, investigate them, and identify/update appropriate interaction patterns and risk treatment options helping to automatically adjust the interaction setting. In other terms, an automated intelligent adaptations and risk management process.

3) A higher consideration of any feedback provided by the user in a direct/indirect, implicit/explicit and conscious/unconsciousway [42], Feedback should be considered as a regulator of design and risk management decisions.

Further, it is assumed that autistic interactive system should hold the attention of autistic users and manage (balance) their engagement. Several techniques were implemented in the literature promoting engagement, such as animated themes, rewards, assisted interaction (wizard) and different kinds of gamification technics. However, it is obvious that all practices do not have the same acceptance levels among user. Accordingly learning from users their 'special 'preferences and adapting the interaction pattern as well as selecting the appropriate technique will contribute to the achievement of interaction goals. We argue for a well-balanced ASD interaction to counterbalance the cost of risks with cognitive user behavior.

\section{Conclusion}

This work is intended to provide a guidance toward a safe autism dedicated interactive systems. It aims to provide stakeholders, HCI designer, developers and therapists, a roadmap identifying autistic dedicated technologies and agreed related risks. Motivate the use of intelligent algorithms for enhancing the contextualization and user centeredness of application scenarios. Urge the involvement and automation of the risk management process to guarantee a safer interaction with autistic peoples where there is always enough space for further development promoting the rehabilitation of autistic people. There is still enough space 
for further development, and better applications for ASDs especially if all parties are involved, such as family members, educators and therapists. Such cooperation can guide the development of technology-based solution that contributes to the rehabilitation of autistic people. Technology advantages for supporting and providing treatment for people with the disability are countless and sometimes vital. For instance, it is found that a continual observation of the patient's behavior will end up receiving the correct diagnosis and can only be achieved by using technology mainly the mobile device that records constantly user states. Further capturing data for assessment, despite the data's complexity, is appreciated by assessment personnel who are optimistic and receptive to new approaches. By looking at the behavior of children with ASD offering a safe and user-center interaction, may have an impact of distressing children with ASD in doing the right activities and interpret and understand the social situation. The interaction scenario must be designed and constructed so as to avoid any health risk due to used device and/or neurological impact. To avoid risks, Machine learning algorithms under shoes a high potential to know and understand the relevant safety rules and directives in detail under the supervision of the expert.

\section{Acknowledgements}

This work does not receive any funding. We thank Shamaah Center for assistance, cooperation and sharing with us their experience during the course of this research.

\section{Conflicts of Interest}

The authors declare no conflicts of interest regarding the publication of this paper.

\section{References}

[1] Van der Gaag, R.-J. (2017) Autism Spectrum Disorders: Developmental History of a Concept. In: Barahona Corrêa, B. and van der Gaag, R.-J., Eds., Autism Spectrum Disorders in Adults, Springer International Publishing, Cham, 1-27. https://doi.org/10.1007/978-3-319-42713-3_1

[2] Reinke, J.S. and Solheim, C.A. (2015) Online Social Support Experiences of Mothers of Children with Autism Spectrum Disorder. Journal of Child and Family Studies, 24, 2364-2373. https://doi.org/10.1007/s10826-014-0039-9

[3] Zheng, Z., Bekele, E., Swanson, A., Weitlauf, A., Warren, Z. and Sarkar, N. (2016) The Impact of Robots on Children with Autism Spectrum Disorder.

[4] Tartaro, A. and Cassell, J. (2006) Using Virtual Peer Technology as an Intervention for Children with Autism. Universal Usability: Designing Computer Interfaces for Diverse User Populations. John Wiley \& Sons, Ltd., New York, 231-262.

[5] Hopkins, I.M., Gower, M.W., Perez, T.A., Smith, D.S., Amthor, F.R., Casey Wimsatt, F. and Biasini, F.J. (2011) Avatar Assistant: Improving Social Skills in Students with an Asd through a Computer-Based Intervention. Journal of Autism and Developmental Disorders, 41, 1543-1555. https://doi.org/10.1007/s10803-011-1179-Z 
[6] Ke, F. and Lee, S. (2016) Virtual Reality Based Collaborative Design by Children with High-Functioning Autism: Design-Based Flexibility, Identity, and Norm Construction. Interactive Learning Environments, 24, 1511-1533. https://doi.org/10.1080/10494820.2015.1040421

[7] Mazurek, M.O., Shattuck, P.T., Wagner, M. and Cooper, B.P. (2012) Prevalence and Correlates of Screen-Based Media Use among Youths with Autism Spectrum Disorders. Journal of Autism and Developmental Disorders, 42, 1757-1767. https://doi.org/10.1007/s10803-011-1413-8

[8] Mazurek, M.O. (2013) Social Media Use among Adults with Autism Spectrum Disorders. Computers in Human Behavior, 29, 1709-1714. https://doi.org/10.1016/j.chb.2013.02.004

[9] Mazurek, M.O. and Wenstrup, C. (2013) Television, Video Game and Social Media Use among Children with ASD and Typically Developing Siblings. Journal of Autism and Developmental Disorders, 43, 1258-1271. https://doi.org/10.1007/s10803-012-1659-9

[10] Khudair, A.A. and Aloshan, M.S. (2015) Caregivers of Autistic Children: Seeking Information in Social Media. International Conference on Information Society, i-Society, 68-72. https://doi.org/10.1109/i-Society.2015.7366861

[11] Pressman, R.M., et al. (2014) Examining the Interface of Family and Personal Traits, Media, and Academic Imperatives Using the Learning Habit Study. The American Journal of Family Therapy, 42, 347-363. https://doi.org/10.1080/01926187.2014.935684

[12] Subrahmanyam, K., Reich, S.M., Waechter, N. and Espinoza, G. (2008) Online and Offline Social Networks: Use of Social Networking Sites by Emerging Adults. Journal of Applied Development Psychology, 29, 420-433. https://doi.org/10.1016/j.appdev.2008.07.003

[13] Lee, S.Y., Lo, Y. and Lo, Y. (2017) Teaching Functional Play Skills to a Young Child with Autism Spectrum Disorder through Video Self-Modeling. Journal of Autism and Developmental Disorders, 47, 2295-2306. https://doi.org/10.1007/s10803-017-3147-8

[14] Buggey, T. (2005) Video Self-Modeling Applications with Students with Autism Spectrum Disorder in a Small Private School Setting. Focus on Autism and Other Developmental Disabilities, 20, 52-63. https://doi.org/10.1177/10883576050200010501

[15] Lillard, A.S. and Peterson, J. (2011) The Immediate Impact of Different Types of Television on Young Children's Executive Function. Pediatrics, 128, 644-649. https://doi.org/10.1542/peds.2010-1919

[16] Bai, Z., Blackwell, A.F. and Coulouris, G. (2015) Using Augmented Reality to Elicit Pretend Play for Children with Autism. IEEE Transactions on Visualization and Computer Graphics, 21, 598-610. https://doi.org/10.1109/TVCG.2014.2385092

[17] Escobedo, L. and Tentori, M. (2014) Mobile Augmented Reality to Support Teachers of Children with Autism. Ubiquitous Computing and Ambient Intelligence, Personalisation and User Adapted Services, Belfast, 2-5 December 2014, Vol. 8867, 60-67. https://doi.org/10.1007/978-3-319-13102-3_12

[18] Nattamai Sekar, L.P., Santos, A. and Beltramello, O. (2015) IMU Drift Reduction for Augmented Reality Applications. In: De Paolis, L.T. and Mongelli, A., Eds., Augmented and Virtual Reality, Springer International Publishing, Cham, 188-196. https://doi.org/10.1007/978-3-319-22888-4_14

[19] Xu, Q., Cheung, S. and Soares, N. (2015) Littlehelper: An Augmented Reality Glass 
Application to Assist Individuals with Autism in Job Interview. Proceedings of APSIPA Annual Summit and Conference.

[20] Mineo, B.A., Ziegler, W., Gill, S. and Salkin, D. (2009) Engagement with Electronic Screen Media among Students with Autism Spectrum Disorders. Journal of Autism and Developmental Disorders, 39, 172-187. https://doi.org/10.1007/s10803-008-0616-0

[21] Bricken, M. (1991) Virtual Reality Learning Environments: Potentials and Challenges. Computer Graphics, 25, 178-184. https://doi.org/10.1145/126640.126657

[22] Hourcade, J.P., Bullock-Rest, N.E. and Hansen, T.E. (2011) Multitouch Tablet Applications and Activities to Enhance the Social Skills of Children with Autism Spectrum Disorders. Personal and Ubiquitous Computing, 16, 157-168. https://doi.org/10.1007/s00779-011-0383-3

[23] Standen, P.J. and Brown, D.J. (2006) Virtual Reality and Its Role in Removing the Barriers That Turn Cognitive Impairments into Intellectual Disability. Journal of Virtual Reality, 10, 241-252.

[24] D’Ateno, P., Mangiapanello, K. and Taylor, B.A. (2003) Using Video Modeling to Teach Complex Play Sequences to a Preschooler with Autism. Journal of Positive Behavior Interventions, 5, 5-11. https://doi.org/10.1177/10983007030050010801

[25] Gal, E., Bauminger, N., Goren-Bar, D., Pianesi, F., Stock, O., Zancanaro, M., et al. (2009) Enhancing Social Communication of Children with High-Functioning Autism through a Co-Located Interface. $A I \&$ Society, 24, 75-84. https://doi.org/10.1007/s00146-009-0199-0

[26] Cappadocia, M.C. and Weiss, J.A. (2011) Review of Social Skills Training Groups for Youth with Asperger Syndrome and High Functioning Autism. Research in Autism Spectrum Disorders, 5, 70-78. https://doi.org/10.1016/j.rasd.2010.04.001

[27] Bauminger, N. (2007) Brief Report: Individual Social-Multi-Modal Intervention for HFASD. Journal of Autism and Developmental Disorders, 37, 1593-1604. https://doi.org/10.1007/s10803-006-0245-4

[28] Bernard-Opitz, V., Sriram, N. and Nakhoda-Sapuan, S. (2001) Enhancing Social Problem Solving in Children with Autism and Normal Children through Computer-Assisted Instruction. Journal of Autism and Developmental Disorders, 31, 377-384. https://doi.org/10.1023/A:1010660502130

[29] Wainer, A.L. and Ingersoll, B.R. (2011) The Use of Innovative Computer Technology for Teaching Social Communication to Individuals with Autism Spectrum Disorders. Research in Autism Spectrum Disorders, 5, 96-107 https://doi.org/10.1016/j.rasd.2010.08.002

[30] Strickland, D. (1997) Virtual Reality for the Treatment of Autism. Studies in Health Technology and Informatics, 44, 81-86.

[31] Chen, W. (2012) Multitouch Tabletop Technology for People with Autism Spectrum Disorder: A Review of the Literature. Procedia Computer Science, 14, 198-207. https://doi.org/10.1016/j.procs.2012.10.023

[32] Benford, P. and Standen, P. (2009) The Internet: A Comfortable Communication Medium for People with Asperger Syndrome (0S) and High Functioning Autism (HFA)? Journal of Assistive Technologies, 3, 44-53. https://doi.org/10.1108/17549450200900015

[33] Burke, R.V., Allen, K.D., Howard, M.R., Downey, D., Matz, M.G. and Bowen, S.L. (2013) Tablet-Based Video Modeling and Prompting in the Workplace for Individuals with Autism. Journal of Vocational Rehabilitation, 38, 1-14.

[34] Murdock, L.C., Ganz, J. and Crittendon, J. (2013) Use of an iPad Play Story to In- 
crease Play Dialogue of Preschoolers with Autism Spectrum Disorders. Journal of Autism and Developmental Disorders, 43, 2174-2189. https://doi.org/10.1007/s10803-013-1770-6

[35] Konstantinidis, E.I., Luneski, A. and Nikolaidou, M.M. (2009) Using Affective Avatars and Rich Multimedia Content for Education of Children with Autism. Proceedings of the 2 nd International Conference on Pervasive Technologies Related to Assistive Environments, Corfu, 9-13 June 2009, Article No. 58.

https://doi.org/10.1145/1579114.1579172

[36] Yee, H.S.S. (2012) Mobile Technology for Children with Autism Spectrum Disorder: Major Trends and Issues. IEEE Symposium on E-Learning, E-Management and E-Services, Kuala Lumpur, 21-24 October 2012.

http://ieeexplore.ieee.org/xpl/login.jsp?tp=\&arnumber=6414954\&url=http\%3A\%2F \%2Fieeexplore.ieee.org\%2Fxpls\%2Fabs_all.jsp\%3Farnumber\%3D6414954

[37] Scottish Intercollegiate Guidelines Network (SIGN) Assessment, Diagnosis and Clinical Intervention for Children and Young People with Autism Spectrum Disorders. A Nation Clinical Guideline.

http://www.autismeurope.org/wp-content/uploads/2017/08/Assessment-diagno-sisand-clinical-interventions-for-children-and-young-people-with-ASD.pdf

[38] Didehbani, N., Allen, T., Kandalaft, M., Krawczyk, D. and Chapman, S. (2016) Virtual Reality Social Cognition Training for Children with High Functioning Autism. Computers in Human Behavior, 62, 703-711.

https://doi.org/10.1016/j.chb.2016.04.033

[39] Litras, S., Moore, D. and Anderson, A. (2010) Using Video Self-Modelled Social Stories to Teach Social Skills to a Young Child with Autism. Autism Research and Treatment, 2010, Article ID: 834979. https://doi.org/10.1155/2010/834979

[40] Anderson, A., Locke, J., Kretzmann, M., Kasari, C. and AIR-B Network (2016) Social Network Analysis of Children with Autism Spectrum Disorder: Predictors of Fragmentation and Connectivity in Elementary School Classrooms. Autism, 20, 700-709. https://doi.org/10.1177/1362361315603568

[41] Mezhoudi, N., Khaddam, I. and Vanderdonckt, J. (2015) Toward Usable Intelligent User Interface. In: Kurosu, M., Ed., Human-Computer Interaction: Interaction Technologies, Lecture Notes in Computer Science, Springer, Berlin, Vol. 9170.

[42] Mezhoudi, N. and Vanderdonckt, L. (2015) A User Feedback Ontology for Context-Aware Interaction. 2nd IEEE World Symposium on Web Applications and Networking, Sousse, 21-23 March 2015, 1-7.

[43] Rasmussen, J. (1983) Skills, Rules, Knowledge: Signals, Signs, and Symbols and Other Distinctions in Human Performance Models. IEEE Transactions on Systems, Man, and Cybernetics, 13, 257-266. https://doi.org/10.1109/TSMC.1983.6313160

[44] Cabibihan, J.J., Javed, H., Aldosari, M., Frazier, T.W. and Elbashir, H. (2017) Sensing Technologies for Autism Spectrum Disorder Screening and Intervention. Sensors, 17, 46.

[45] Purdy, G. (2010) ISO 31000: 2009-Setting a New Standard for Risk Management. Risk Analysis: An International Journal, 30, 881-886. https://doi.org/10.1111/j.1539-6924.2010.01442.x

[46] International Organization for Standardization (2009) ISO 31000: Risk Management: Principles and Guidelines. ISO.

[47] Victoria, L. and Dunckley, M.D. (2016) Autism and Screen Time: Special Brains, Special Risks Children with Autism Are Vulnerable to the Negative Effects of Screen Time. 
[48] Rowan, C. (2010) The Impact of Technology on Child Sensory and Motor Development. http://www.sensoryprocessing.info/CrisRowan.pdf

[49] Just, K. and Kana (2013) A Theory of Autism Based on Frontal-Posterior Underconnectivity. In: Development and Brain Systems in Autism, Psycologicy Press, New York, 35-63.

[50] Swing, E.L., et al. (2010) Television and Video Game Exposure and the Development of Attention Problems. Pediatrics, 126, 214-221.

[51] William, T. (2013) Risks: Human Factors and Behavioral Performance (HFBP) NASA. https://humanresearchroadmap.nasa.gov/Risks/risk.aspx?i=164 